\title{
Hypersensitivity to aspirin: Common eicosanoid alterations in urticaria and asthma
}

\author{
Lucyna Mastalerz, MD, PhD, Malgorzta Setkowicz, MD, Marek Sanak, MD, PhD, and \\ Andrew Szczeklik, MD, PhD* Krakow, Poland
}

\begin{abstract}
Background: Aspirin and other nonsteroidal anti-inflammatory drugs (NSAIDs) can precipitate adverse reactions in two apparently different clinical conditions: bronchial asthma and chronic idiopathic urticaria (CIU). Recent evidence indicates that the reactions are triggered by the drugs that inhibit cyclooxygenase-1 but not cyclooxygenase-2.

Objective: To assess whether patients with CIU and aspirin sensitivity share common eicosanoid alterations with patients who have aspirin-sensitive asthma.

Methods: Seventy-four patients with CIU and a history of sensitivity to aspirin and NSAIDs underwent placebocontrolled oral aspirin challenge tests. Concentrations of urinary leukotriene E4 (uLTE4) were measured by ELISA and plasma stable prostaglandin D2 metabolite, $9 \alpha, 11 \beta$ prostaglandin $F_{2}$ by GC/MS. All measurements were carried out at baseline and after aspirin dosing. Patients were genotyped for the leukotriene C4 synthase (LTC4S) promoter single nucleotide polymorphism.

Results: In 30 of $\mathbf{7 4}$ patients, the aspirin challenge was positive, resulting in urticaria/angioedema. In these 30 patients, baseline uLTE4 levels were higher than in nonresponders and the healthy control subjects and increased further (significantly) after the onset of clinical reaction. No such increase occurred in subjects with negative aspirin challenge. Baseline uLTE4 levels correlated with severity of skin reactions. Plasma $9 \alpha, 11 \beta$ prostaglandin $F_{2}$ levels rose significantly in both aspirin responders and nonresponders, although in the latter group the increase occurred later than in the former. In patients who reacted to aspirin, frequency of ${ }_{-444} \mathrm{C}$ allele of LTC4S was significantly higher than in patients who did not react.

Conclusions: CIU with aspirin sensitivity is characterized by the eicosanoid alterations, which are similar to those present in aspirin-induced asthma. (J Allergy Clin Immunol 2004;113:771-5.)
\end{abstract}

Key words: Urticaria, eicosanoids, aspirin, NSAIDs, asthma

Shortly after its introduction into therapy, aspirin was implicated as the cause of an anaphylactic reaction. The first case report of acute angioedema/urticaria was published in $1902{ }^{1}$ Soon it was realized that aspirin might also precipitate violent acute bronchospasm. Over the years, it became evident that aspirin-induced asthma (AIA), as it started to be called, is a distinct clinical

\footnotetext{
From the Departments of Medicine and Dermatology, Jagiellonian University School of Medicin, Kracow, Poland

Received for publication July 25, 2003; revised December 19, 2003; accepted for publication December 22, 2003.

Reprint requests: Andrzej Szczeklik, MD, PhD, Jagiellonian University,

School of Medicine, Department of Medicine, ul. Skawinska 8, $31-066$

Kraków, Poland.

0091-6749/\$30.00

(C) 2004 American Academy of Allergy, Asthma and Immunology doi:10.1016/j.jaci.2003.12.323
}

syndrome affecting $5 \%$ to $10 \%$ of adults with asthma. ${ }^{2,3}$ It develops according to a characteristic sequence of symptoms and follows a clinical course that is similar all over Europe ${ }^{4}$ and in the United States. ${ }^{5}$ Asthmatic attacks triggered by aspirin are associated with inhibition of cyclooxygenase, ${ }^{6}$ specifically COX-1 but not COX-2, and are characterized by overproduction of cysteinyl leukotrienes. ${ }^{3}$ The interest in AIA has been recently enhanced by introduction into therapy of leukotriene receptor antagonists ${ }^{7}$ and by discovery of new cyclooxygenases. ${ }^{8}$

In contrast to AIA, progress in understanding urticaria/ angioedema sensitive to aspirin has been slow. Clinicians have been well aware that up to $40 \%$ of patients with chronic urticaria have an increase in wheals and swelling after aspirin. It was reported that in some of them not only aspirin but several other NSAIDs that inhibit COX precipitated skin eruptions. ${ }^{9}$ However, no studies on eicosanoid metabolism have been carried out.

We and others ${ }^{10-15}$ have observed recently that coxibs, selective COX-2 inhibitors, do not precipitate wheals and swelling in patients with chronic urticaria who are sensitive to aspirin. Furthermore, we also noticed that NSAID sensitivity in urticaria is associated with overproduction of cysLTs, as reflected by increased basal excretion of $\mathrm{LTE}_{4} \cdot{ }^{10,11}$ These data were reminiscent of aspirin-induced asthma. ${ }^{3}$ We therefore decided to study in a group of patients with chronic idiopathic urticaria (CIU) effects of aspirin on two major mediators: cys-LTs and prostaglandin $(\mathrm{PG}) \mathrm{D}_{2}$.

\section{METHODS \\ Subjects}

The study population consisted of 74 patients with CIU in apparent remission, that is, without any skin symptoms for at least 4 weeks preceding the study (Table I). Diagnosis of CIU required presence of urticaria and/or angioedema every day or almost every day for more than 6 weeks over the last 0.5 to 6 years. All patients gave the history of skin reactions after the ingestion of aspirin or other NSAIDs but had no history of asthma, nasal polyps, or anaphylaxis. Two weeks before beginning of the study, any local steroids or antihistamines and leukotriene receptor antagonists were stopped. Patients were asked to avoid over-the-counter medications and food with artificial flavoring or preservatives. A group of healthy control subjects for comparison of basal urinary $\mathrm{LTE}_{4}$ and plasma $9 \alpha, 11 \beta \mathrm{PGF}_{2}$ levels consisted of 52 healthy subjects (Table I). They were healthy and had no history of $\mathrm{CIU}$, asthma, or atopic diseases. The patients gave informed consent, and the study was approved by the University Ethics Committee.

\section{Study design}

After a 2-week run-in period, the patients underwent aspirin testing. The single-blind, placebo-controlled oral challenge test with aspirin was carried out on 2 consecutive days. On day 1, 3 capsules of 


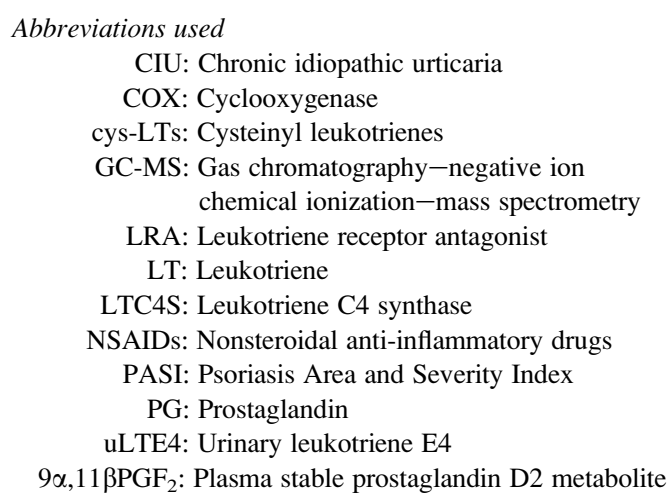

placebo were administered every hour. On day 2 , the patients were challenged with increasing doses of 71,117, and $312 \mathrm{mg}$ of aspirin at 1-hour intervals. Aspirin and placebo had identical appearance. The challenge procedure with aspirin was interrupted if a cutaneous reaction was observed or when extracutaneous symptoms (bronchospasm, rhinorrhoea, nasal congestion) appeared or if the maximum cumulative dose of aspirin was reached.

$\mathrm{FEV}_{1}$ and skin reactions were recorded at baseline, before the challenge tests, and then every 15 minutes until 6 hours after the last dose of aspirin or placebo. In patients with positive aspirin challenge, urine samples were collected for $\mathrm{LTE}_{4}$ estimations at baseline, at the time of appearance of the first skin symptoms (time 0 ), and then 2 and 4 hours later. In nonresponders, the urine samples were collected at baseline, 1 hour after the last aspirin dosing, that is, when the cumulative dose of $500 \mathrm{mg}$ was reached (time 0 ), and then 2 and 4 hours later.

Blood for determination of the $\mathrm{PGD}_{2}$ stable metabolite $9 \alpha, 11 \beta \mathrm{PGF}_{2}$ was collected at baseline, at the time of appearance of the first skin symptoms after aspirin challenge (time 0), and 60, 120, and 240 minutes after the appearance of skin reaction. In nonresponders, blood was drawn at baseline, 1 hour after reaching the dose $500 \mathrm{mg}$ aspirin (time 0 ), and then 60, 120, and 240 minutes later.

Genomic DNA samples were obtained from peripheral blood of 71 patients (29 reacting to aspirin challenge and 42 nonreacting to aspirin).

\section{Assessment of severity of skin eruption}

To standardize the assessment of severity of the skin eruptions, a modified PASI (Psoriasis Area and Severity Index) score was used. ${ }^{16}$ For the assessment of urticaria, itching replaced desquamation in the index. Thus, we determined the degree of itching, erythema, and infiltration, expressed as a percentage of involvement of the four main body areas: head, trunk, upper extremity, and lower extremity. Each variable was assessed on a scale of 0 to 4 , with 0 indicating no skin involvement and 4 indicating the severe involvement. Calculated PASI score could range from 0 to 72 , with 0 indicating no reaction at all and 72 a very serious reaction affecting most of the body. We considered PASI $\geq 10$ as severe reaction. PASI score determinations were carried out by an experienced dermatologist at the time of the first appearance of skin lesions and 2, 4, and 6 hours later.

\section{Lung function}

Pulmonary functiontestswereperformed on aflow-integrating computerized pneumotachograph (Pneumocsreen, E. Jaeger, Germany).

\section{Biochemical assays}

Urinary $\mathrm{LTE}_{4}$ was measured in unpurified urine samples by direct enzyme immunoassay (Cayman Chemical, Ann Arbor, Mich). ${ }^{17}$ Measurements were made at the same time, in duplicates, using the same kit, and expressed in nanograms per milligram of creatinine.
$9 \alpha, 11 \beta \mathrm{PGF}_{2}$ was measured in plasma by gas chromatographynegative ion chemical ionization-mass spectrometry (GC-MS, Hewlett Packard, Palo Alto, Calif) after the extraction stage, through use of a C18 Sep-Pak cartridge, derivatization to pentafluorobenzyl ester, thin-layer chromatography purification, and derivatization to trimethylsilyl ether. $\left[^{2} \mathrm{H}_{4}\right] 9 \alpha, 11 \beta \mathrm{PGF}_{2} \alpha$ was used as an internal standard in a manner identical to gas chromatography-electron impact mass spectrometry, as reported by Obata et al. ${ }^{18}$ Results are expressed in picograms per milliliter.

The LTC $_{4}$ synthase single nucleotide polymorphism at a site 444 nucleotides upstream of the translation start was genotyped as described previously. ${ }^{19}$

\section{Statistical analysis}

Statistical evaluation was carried out with the use of a personal computer and STATISTICA software (Statsoft Inc). Summary statistics were expressed as median and $25 \%$ and $75 \%$ percentiles. A multiway ANOVA model, including time as a repeated-measure factor, other factors, and all possible interactions, was used for multiple-group comparisons. The logarithmic transformation was used, when needed, as a variance stabilizing transformation. The post hoc Tukey procedure was used for multiple comparisons. Fisher exact test was used for dichotomous data for two independent random samples. A $P$ value $\leq .05$ was considered statistically significant.

\section{RESULTS \\ Clinical reactions}

None of the patients had symptoms after administration of placebo. Thirty patients challenged with aspirin had cutaneous rash. There was no statistical difference in clinical characteristics between the patients with positive aspirin challenge test and the nonresponders (Table I). Skin reactions developed after $71 \mathrm{mg}$ in 1 subject, after $188 \mathrm{mg}$ in 9 subjects, and after $500 \mathrm{mg}$ of cumulative dose of acetylsalicylic acid in 20. The clinical appearance of the rash was consistent with urticaria and angioedema. In 11 patients, PASI score was $\geq 10$, and these patients were therefore considered to have severe reactions, whereas in the remaining 19 patients, PASI score was $<10$.

In 27 of 30 patients who reacted to aspirin, the challenge produced no dyspnea, and spirometic values remained stable throughout the observation period. One patient, after ingestion of aspirin at a dose $188 \mathrm{mg}$, and 2 others after a dose of $500 \mathrm{mg}$, had rhinorrhea, conjunctivitis, and shortness of breath, with $\mathrm{FEV}_{1}$ drop exceeding 20\%; all these symptoms preceded development of urticaria. The urinary baseline $\mathrm{LTE}_{4}$ in these 3 subjects who had dual respiratory/urticarial response were as follows: 592, 538, and $1095 \mathrm{ng} / \mathrm{mg}$ creatinine; the peak values after aspirin were 4375,676 , and $1819 \mathrm{ng} / \mathrm{mg}$ creatinine, respectively. Baseline 9 $\alpha, 11 \beta$ PGF2 values were 5.1, 4.9, and $4.2 \mathrm{pg} / \mathrm{mL}$; the peak values reached after aspirin were 15.5 , 5.9 , and $5.7 \mathrm{pg} / \mathrm{mL}$, respectively.

\section{Urinary $\mathrm{LTE}_{\mathbf{4}}$}

Baseline urinary $\mathrm{LTE}_{4}$ excretion (Table I) was higher in patients with a positive aspirin test than in patients with a negative aspirin test $(P=.005)$. The latter group, in turn, differed from healthy subjects $(P=.0001)$. Urinary $\mathrm{LTE}_{4}$ levels did not increase at 2 hours $(P=.07)$ and increased 


\begin{tabular}{|c|c|c|c|}
\hline & \multicolumn{2}{|c|}{ Patients } & \multirow[b]{2}{*}{$\begin{array}{l}\text { Healthy control } \\
\text { subjects }(n=48)\end{array}$} \\
\hline & $\begin{array}{l}\text { Aspirin challenge } \\
\text { positive }(\mathbf{n}=\mathbf{3 0})\end{array}$ & $\begin{array}{l}\text { Aspirin challenge } \\
\text { negative }(n=44)\end{array}$ & \\
\hline Sex W/M & $23 / 7$ & $32 / 12$ & $35 / 13$ \\
\hline Age, y & $48(34-52)$ & $42(28-49)$ & $43(30-48)$ \\
\hline Total IgE, IU/mL & $132.5(64.6-233)$ & $93.0(31.4-324.5)$ & - \\
\hline Duration of urticaria, y & $2(1-5)$ & $2(0.5-6)$ & - \\
\hline Urinary $\mathrm{LTE}_{4} \mathrm{ng} / \mathrm{mg}$ creatinine & $535.5(270.0-1026)$ & $285.5(178.0-390.0)$ & $110.0(58.0-152.0)$ \\
\hline Plasma $9 \alpha, 11 \beta \mathrm{PGF}_{2} \mathrm{pg} / \mathrm{mL}$ & $4.85(3.80-6.10)$ & $4.25(3.05-6.04)$ & $4.55(2.9-6.0)$ \\
\hline \multicolumn{4}{|l|}{ Genotype of $\mathrm{LTC}_{4} \mathrm{~S}$} \\
\hline AA & 9 & 26 & \\
\hline $\mathrm{AC}$ & 16 & 13 & \\
\hline $\mathrm{CC}$ & 4 & 3 & \\
\hline
\end{tabular}

Median (25\% to $75 \%$ percentiles; lower and upper quartile).

at 4 hours $(P=.03)$ after aspirin challenge tests, as compared with baseline values, only in the group of patients with the positive aspirin challenge (Fig 1).

At baseline and after aspirin challenge, urinary $\mathrm{LTE}_{4}$ levels were the highest in patients with severe skin reactions (PASI score $\geq 10$ ). They differed significantly from patients with PASI score $<10(P=.002)$ and from the group of aspirin nonresponders $(P<.001)$. There was a moderate correlation between the baseline urinary levels of $\mathrm{LTE}_{4}$ and the maximal intensity of skin eruption expressed as PASI score (Pearson $\mathrm{r}=0.42 ; P=.02$ ).

\section{Plasma 9 $\alpha, 11 \beta \mathrm{PGF}_{2}$}

At baseline (Table I), plasma levels of $9 \alpha, 11 \beta \mathrm{PGF}_{2}$ did not differ between the three groups. After aspirin challenge, plasma concentrations of $9 \alpha, 11 \beta \mathrm{PGF}_{2}$ rose significantly in the group of patients who had clinical reaction $(P=.03)$. They reached the peak 60 minutes after the onset of clinical reaction and returned to baseline values 1 hour later. An increase in the $\mathrm{PGD}_{2}$ metabolite was recorded also in the group of patients who did not have a clinical reaction to aspirin. The rise appeared to proceed at slower pace; it reached the peak 120 minutes after the cumulative dose of aspirin and approached the baseline levels only 2 hours later (Fig 2). The dose of aspirin had no effect on magnitude of the response of $9 \alpha, 11 \beta \mathrm{PGF}_{2}$ and its duration. There was a tendency for higher baseline plasma concentrations of $9 \alpha, 11 \beta \mathrm{PGF}_{2}$ in patients with severe skin reactions (difference between the groups with PASI score $\geq 10$ and $<10$ was $P=.07$ ).

$\mathrm{LTE}_{4}$ and $9 \alpha, 11 \beta \mathrm{PGF}_{2}$ levels were not measured in healthy subjects because they were previously documented not to change after aspirin challenge. ${ }^{20,21}$

\section{LTC $_{\mathbf{4}}$ synthase genotyping}

There were 35 (49.3\%) individuals homozygous for the wild-type allele (AA), 29 (40.8\%) heterozygous, and 7 $(9.9 \%)$ homozygous for ${ }_{-444} \mathrm{C}$ allele (CC). Genotype distribution of $\mathrm{LTC}_{4} \mathrm{~S}$ polymorphism in patients with positive aspirin challenge was $31 \%$ (AA), $55.2 \%$ (AC), and $13.8 \%(\mathrm{CC})$, whereas among patients with negative challenge, there were $61.9 \%$ (AA), $31 \%$ (AC), and $7.1 \%$ (CC). In both groups of patients, genotype frequencies followed genetic equilibrium, though in aspirin re- sponders $-444 \mathrm{C}$-positive genotypes (AC or $\mathrm{CC}$ ) were significantly more common $(P<.01$, Fisher exact test). Accordingly, frequency of ${ }_{-444} \mathrm{C}$ allele in patients who reacted to aspirin was significantly higher than in patients who did not react ( $q=0.414$ vs $q=0.226 ; P=.016$, Fisher exact test). The genotype and allele frequencies of the negative challenge group did not differ from population data on healthy subjects. ${ }^{37}$

\section{DISCUSSION}

All the patients studied by us had CIU and gave a history suggestive of aspirin sensitivity. When challenged with aspirin, only $40 \%$ had positive skin response. This clearly shows that aspirin hypersensitivity needs to be confirmed by provocation testing and also that it may show temporary fluctuations. The number of $40 \%$ aspirin responders corresponds to the upper level reported by the other authors ${ }^{22,23}$ in an unselected population of CIU. Perhaps higher doses of aspirin exceeding $500 \mathrm{mg}$ might have provoked a reaction in some negative patients.

The group of aspirin-sensitive patients had at baseline markedly elevated urinary $\mathrm{LTE}_{4}$ levels, which distinguished them from both aspirin-tolerant CIU patients and the control group. Urinary $\mathrm{LTE}_{4}$ values were the highest in the patients with most severe skin reactions. These results confirm our recent preliminary observations. ${ }^{10,11}$ A novel finding is that aspirin precipitated a further statistically significant rise in urinary $\mathrm{LTE}_{4}$ as compared with baseline values only in the group of patients who had clinical reactions after the response to challenge. When $\mathrm{Di}$ Lorenzo et $\mathrm{al}^{24}$ compared urinary $\mathrm{LTE}_{4}$ levels in $5 \mathrm{CIU}$ patients sensitive to aspirin with $10 \mathrm{CIU}$ tolerating aspirin well, they found no difference at baseline but an increase in $\mathrm{LTE}_{4}$ after aspirin only in the former group. In vitro, release of cys-LTs by peripheral blood leukocytes from aspirin-sensitive asthmatic patients is dependent on $\mathrm{PGE}_{2}$ biosynthesis, which becomes impaired by nonsteroidal anti-inflammatory drugs. ${ }^{25}$ Our results might also explain good clinical response to therapy with leukotriene receptor antagonists (LRAs), reported ${ }^{26,27}$ in most patients with chronic urticaria and aspirin sensitivity.

Cys-LTs, of which $\mathrm{LTE}_{4}$ is the final urinary metabolite, can be produced by eosinophils and basophils. Both these 


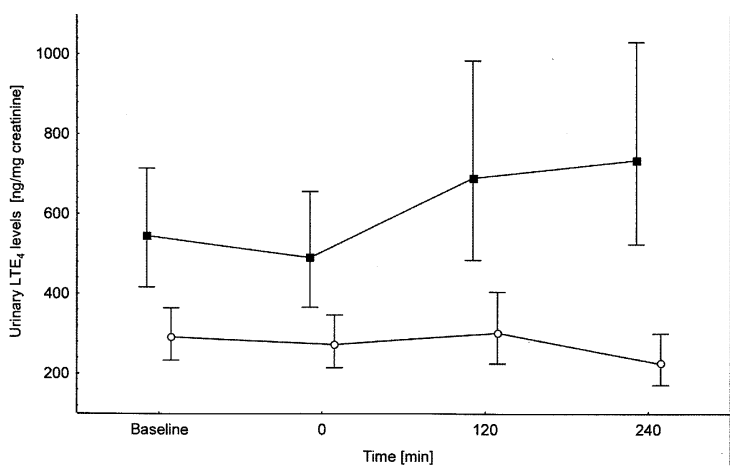

FIG 1. Urinary $\mathrm{LTE}_{4}$ levels (means and $95 \% \mathrm{Cl}$ ) after aspirin challenge in 30 patients with $\mathrm{CIU}$ who responded with clinical reaction (squares) and in 44 patients with $\mathrm{CIU}$ who showed no clinical response (open circles). In responders, urine was collected at baseline, at the time of appearance of the first symptoms (time $0)$, and then 2 and 4 hours later. In nonresponders, urine was collected at baseline, 1 hour after reaching $500 \mathrm{mg}$ aspirin (time 0 ), and then 2 and 4 hours later. Baseline urinary LTE4 was significantly higher in aspirin-positive patients and increased significantly after aspirin only in this group. Mean values of urinary $\mathrm{LTE}_{4}$ levels are expressed as $\mathrm{ng} / \mathrm{mg}$ creatinine.

cells are a rich source of eicosanoids and both are believed to play important role in CIU. We therefore studied release of another eicosanoid, that is, $\mathrm{PGD}_{2}$. This is the predominant cyclooxygenase metabolite of arachidonic acid in mast cells but not in basophils. ${ }^{28}$ Because of rapid metabolism and artifactual generation of prostaglandins during sampling and isolation of plasma, it is recognized that measuring metabolites rather than the parent compound is the most efficacious method of assessing the prostaglandin's endogeneous production. $9 \alpha, 11 \beta \mathrm{PGF}_{2}$ is a major stable metabolite of $\mathrm{PGD}_{2}$, which in fact boast biological activity. The mass spectrometry measurement of $9 \alpha, 11 \beta \mathrm{PGF}_{2}$ in blood is highly accurate and sensitive.

Using this method, we have recently demonstrated ${ }^{21}$ that in patients with AIA, as opposed to healthy subjects, aspirin challenge precipitated the clinical reaction, accompanied by a rise in plasma levels of the $\mathrm{PGD}_{2}$ metabolite. A similar rise was observed in the patients with CIU. This phenomenon occurred both in patients who had urticaria/ angioedema after aspirin challenge and in those who did not. Although $\mathrm{PGD}_{2}$ release appeared to occur earlier in clinical responders than in nonresponders, the peak values reached were similar. Thus, target cells, most likely mastocytes, had an enhanced propensity to release $\mathrm{PGD}_{2}$, perhaps being sensitized by autoantibodies, ${ }^{29-34}$ but this remains to be proved. It is interesting to note that clinical signs and laboratory markers of autoimmunity were reported in some patients with aspirin-induced asthma. ${ }^{35}$

Demonstration of histamine release from healthy donor basophil or mast cells remains the gold standard for establishing an autoimmune basis of CIU. ${ }^{32}$ There are good reasons toconsiderhistamine aleading mediatorin urticaria. Our results indicate that cys-LTs and $\mathrm{PGD}_{2}$ should also be taken into consideration. This notion gets support from a study on local effects of eicosanoids in human skin. CysLTs in nanomolar amounts were able to induce cutaneous

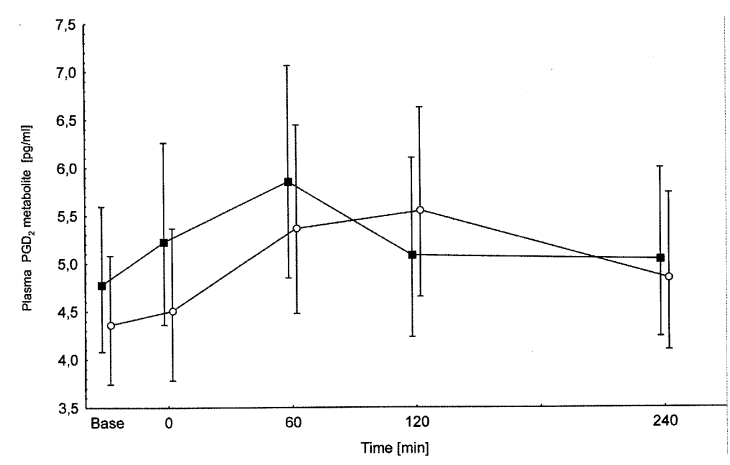

FIG 2. Plasma $9 \alpha, 11 \beta \mathrm{PGF}_{2}$ levels (means and $95 \% \mathrm{Cl}$ ) after aspirin challenge in 30 patients with $\mathrm{CIU}$ who had clinical response (squares) and in 44 nonresponders (open circles). In the responders, blood was drawn before the challenge (baseline), at the time of appearance of symptoms (time 0), and 60, 120, and 240 minutes later. In nonresponders, blood was drawn at baseline, 1 hour after reaching the dose $500 \mathrm{mg}$ aspirin (time 0), and 60, 120, and 240 minutes later. In both groups, the $\mathrm{PGD}_{2}$ metabolite studied increased significantly after aspirin challenge, though the course of increase was not the same. Mean values of plasma levels of $9 \alpha, 11 \beta \mathrm{PGF}_{2}$ are expressed as $\mathrm{pg} / \mathrm{mL}$.

vasodilation with edema formation and a neutrofil infiltrate, and these responses were enhanced by $\mathrm{PGD}_{2}{ }^{36}$

Inheritance of the allelic variant $-444 \mathrm{C}$ of $\mathrm{LTC}_{4}$ synthase, which we attributed to moderately enhanced expression of the enzyme, ${ }^{37}$ appears to associate with aspirin-triggered $\mathrm{CIU}$ in a manner similar to aspirininduced asthma. Though not confirmed by replication studies, ${ }^{38,39}$ this variant correlated with capacity for cysteinyl leukotrienes biosynthesis ${ }^{40}$ or with clinical response to cysteinyl leukotreine antagonist. ${ }^{41}$ Detection of the genetic association between $\mathrm{LTC}_{4}$ synthase polymorphism and aspirin-triggered $\mathrm{CIU}$, second to severe AIA, ${ }^{3}$ corroborates the hypothesis on common mechanisms underlying these two clinical syndromes.

Finally, our data point to emerging basic similarities between the two distinct clinical syndromes with sensitivity to aspirin, that is, CIU and rhinitis/asthma. These syndromes, cared for by different specialists, may occur simultaneously in the same patient, without him being even aware of this, as was the case in 3 of 30 subjects studied by us. The similarities that we are referring to can be summarized as follows: (1) Clinical reactions (either cutaneous or bronchial) are precipitated by the drugs that inhibit COX-1 but not COX-2. (2) Baseline urinary $\mathrm{LTE}_{4}$ levels, believed to reflect global cys-LTs biosynthesis, are markedly increased. (3) Ingestion of aspirin leads to further massive release of cys-LTs. (4) Aspirin releases $\mathrm{PGD}_{2}$ in both aspirin-sensitive asthmatic patients and in patients with CIU and a history of NSAID intolerance.

Perhaps aspirin, by depleting protective $\mathrm{PGE}_{2},{ }^{42,43}$ promotes unrestrained synthesis of cys-LTs and release of mediators such as $\mathrm{PGD}_{2}$ from mast cells. Our results might help explain both the pathophysiology of CIU (cys-LTs cause vascular permeability, which becomes enhanced by $\mathrm{PGD}_{2}$ ), as well as good clinical response to LRA in several patients with CIU. We still do not know the reasons for 
profound alterations in basal eicosanoid biosynthesis in the two syndromes discussed. Latent viral infection and autoimmunity remain fascinating possible mechanisms for future studies.

\section{REFERENCES}

1. Settipanne GA. Landmark commentary: history of aspirin intolerance. Allergy Proc 1990;11:251-3.

2. Samter M, Beers RF. Intolerance to aspirin: clinical studies and consideration of its pathogenesis. Ann Intern Med 1968;68:975-83.

3. Szczeklik A, Stevenson DD. Aspirin-induced asthma: advances in pathogenesis, diagnosis, and management. J Allergy Clin Immunol 2003; 111:913-21.

4. Szczeklik A, Nizankowska E, Duplaga M, on behalf of the AIANE Investigators. Natural history of aspirin-induced asthma. Eur Respir J 2000; $16: 432-6$

5. Berges-Gimeno MP, Simon RA, Stevenson DD. The natural history and clinical characteristics of aspirin exacerbated respiratory disease. Ann Allergy Asthma Immunol 2002;89:472-8.

6. Szczeklik A, Gryglewski RJ, Czerniawska-Mysik G. Relationship of inhibition of prostaglandin biosynthesis by analgesics to asthma attacks in aspirin-sensitive patients. Br Med J 1975;1:67-9.

7. Folco G, Samuelsson B, Murphy RC. Novel inhibitors of leukotrienes. Basel/Boston: Birkhauser Verlag; 1999.

8. Chandrasekharan NV, Dai H, Roos KL, Evanson NK, Tomsik J, Elton TS, et al. COX-3, a cyclooxygenase-1 variant inhibited by acetaminophen and other analgesic/antipyretic drugs: cloning, structure, and expression. Proc Natl Acad Sci U S A 2002;99:13926-31.

9. Szczeklik A, Gryglewski RJ, Czerniawska-Mysik G. Clinical patterns of hypersensitivity to nonsteroidal antiinflammatory drugs and their pathogenesis. J Allergy Clin Immunol 1977;60:276-84.

10. Setkowicz M, Zembowicz A, Mastalerz L, Radziszewski W, Szczeklik A. Non-steroidial anti-inflammatory drugs (NSAID) sensitivity in chronic idiophatic urticaria CIU: selective involvement of cyclooxygenase 1 (COX-1) and overproduction of cysteinyl-leukotrienes. J Allergy Clin Immunol 2003;111:S272.

11. Zembowicz A, Mastalerz L, Setkowicz M. Radziszewski W, Szczeklik A. Safety of cyclooxygenase II inhibitors and increased leukotriene synthesis in chronic idiophatic urticaria with sensitivity to non-steroidial anti-inflammatory drugs. Arch Dermatol 2003;139:1577-82.

12. Berges-Gimeno MP, Camacho-Garrido E, Garcia Rodriguez RM, Martin-Garcia C, Alfaya-Arias T, Prieto P, et al. Rofecoxib, a slelective high affinity COX-2 inhibitor has proved to be safe in urticaria/ angioedema associated with NSAID intolerance. Allergy 2001;56:49.

13. Pacor ML, Di Lorenzo G, Biasi D, Corrocher R. Safety of rofecoxib in subjects with a history of adverse cutaneous reactions to aspirin and/or nonsteroidial anti-inflammatory drugs. Clin Exp Allergy 2002;109:S140.

14. Nettis E, Di PR, Ferrannini A, Tursi A. Tolerability of rofecoxib in patients with cutaneous adverse reactions to nonsteroidial anti-inflammatory drugs. Ann Allergy Asthma Immunol 2002:88331-4.

15. Sanchez-Borges M, Capriles-Hulett A, Caballero-Fonesca F. How safe are COX-2 inhibitors in NSAID-sensitive subjects with cutaneous reactions. ACI Int 2003; 15:110-3.

16. . Frederiksson T, Pettersson U. Severe psoriasis: oral therapy with new retinoid. Dermatologica 1978;157:238-44.

17. Kumlin M, Stensvad L, Larsson L, Dahlen B, Dahlen SE. Validation and application of a new simple strategy for measurements of urinary leukotriene $\mathrm{E}_{4}$ in humans. Clin Exp Allergy 1995;25:467-79.

18. Obata T, Nagakura T, Kammuri M, Masaki T, Maekawa K, Yamashita $\mathrm{K}$. Determination of $9 \alpha 11 \beta-$ prostaglandin $\mathrm{F}_{2}$ in human urine and plasma by gas chromatography-mass spectrometry. J Chromatogr 1994; 655:173-8

19. Sanak M, Simon H-U, Szczeklik A. Leukotriene $\mathrm{C}_{4}$ synthase promoter polymorphism and risk of aspirin-induced asthma. Lancet 1997;350:1599-600.

20. Nasser SM, Lee TH. Leukotrienes and aspirin-sensitive asthma. In: Szczeklik A, Gryglewski R, Vane J, editors. Eicosanoids, aspirin and asthma New York: Marcel Dekker Inc; 1998. p. 317-33.

21. Bochenek G, Nagraba K, Nizankowska E, Szczeklik A. A controlled study of $9 \alpha, 11 \beta-\mathrm{PGF}_{2}$ (a prostaglandin $\mathrm{D}_{2}$ metabolite) in plasma and urine of patients with bronchial asthma and healthy controls after aspirin challenge. J Allergy Clin Immunol 2003;111:743-9.
22. Juhlin L. Recurrent urticaria: clinical investigation of 330 patients. Br J Dermatol 1981;104:369-81.

23. Stevenson DD, Simon RA. Sensitivity to aspirin and nonsteroidal anti inflammatory drugs. In: Middleton E, edtior. Allergy. Principles and practice. St Louis: Mosby; 1998. p. 1225-34

24. Di Lorenzo G, Pacor ML, Vignola AM, Profita M, Esposito-Pellitteri M, Biasi D, et al. Urinary metabolites of histamine and leukotrienes before and after placebo-controlled challenge with ASA and food additives in chronic urticaria patients. Allergy 2002;57:1180-6

25. Celik G, Bavbek S, Misirligil Z, Melli M. Release of cysteinyl leukotrienes with aspirin stimulation and the effect of prostaglandin $E_{2}$ on this release from peripherial blood leucocytes in aspirin-induced asthmatic patients. Clin Exp Allergy 2001;31:1615-22.

26. Pacor ML, Di Lorenzo G, Corrocher R. Efficacy of leukotriene receptor antagonist in chronic urticaria: a double-blind comparison of treatment with montelukast and cetirizine in patients with chronic urticaria with intolerance to food additive and/or acetylsalicylic acid. Clin Exp Allergy 2001;31:1607-14.

27. Erbagci Z. The leukotriene receptor antagonist montelukast in the treatment of chronic idiopathic urticaria: a single-blind, placebo-controlled, crossover clinical study. J Allergy Clin Immunol 2002;110:484-8.

28. Marone G, Lichtenstein LM, Galli SJ. Mast cells and basophils. San Diego: Academic Press; 2000.

29. Hide M, Francis DM, Grattan CEH, Hakimi J, Kochan JP, Greaves MW. Autoantibodies against the high-affinity $\operatorname{IgE}$ receptor as a cause of histamine release in chronic urticaria. N Engl J Med 1993;328:1599-604.

30. Fiebiger E, Maurer D, Holub H, Reininger B, Hartman G, Wolsetschläger $\mathrm{M}$, et al. Serum IgG autoantibodies directed against the $\alpha$ chain of Fc\&RI: a selective marker and pathogenetic factor for a distinct subset of chronic urticaria patients? J Clin Invest 1995;96:2606-12.

31. Ferrer M, Kinet J-P, Kaplan AP. Comparative studies of functional and binding assays for IgG anti-FceRI $\alpha$ ( $\alpha$-subunit) in chronic urticaria. J Allergy Clin Immunol 1998;101:672-6.

32. Greaves MW. Pathophysiology of chronic urticaria. Int Arch Allergy Immunol 2002;127:3-9.

33. Kaplan A. Chronic urticaria and angioedema. N Engl J Med 2002;346: 175-9.

34. Asero R, Tedeshi A, Lorini M. Autoreactivity is highly prevalent in patients with multiple intolerances to NSAIDs. Ann Allergy Asthma Immunol 2002;88:468-72.

35. Szczeklik A, Niżankowska E, Serafin A, Dyczek A, Duplaga M, Musial J. Autoimmune phenomena in bronchial asthma with special reference to aspirin intolerance. Am J Respir Crit Care Med 1995;152:1753-6.

36. Soter NA, Lewis RA, Corey EJ, Austen KF. Local effects of synthetic leukotrienes (LTC4, LTD4, LTE4, and LTB4) in human skin. J Investig Dermatol 1983;80:115-9.

37. Sanak M, Pierzchalska M, Bazan-Socha S, Szczeklik A. Enhanced expression of the leukotriene $\mathrm{C} 4$ synthase due to overactive transcription of an allelic variant associated with aspirin-intolerant asthma. Am J Respir Cell Med Biol 2000;23:290-6.

38. Van Sambeek R, Stevenson D, Baldasaro M, Lam BK, Zhao J, Satoshi $\mathrm{Y}$, et al. 5'Flanking region polymorphism of the gene encoding leukotriene $\mathrm{C}_{4}$ synthase does not correlate with the aspirin-intolerant phenotype in the United States. J Allergy Clin Immunol 2000;106:72-6.

39. Sayers I, Barton S, Rorke S, Beghé, Hayward B, Van Eerdewegh P, et al. Allelic association and functional studies of promoter polymorphism in the leukotriene C4 synthase gene (LTC4S) in asthma. Thorax 2003;58: 417-27.

40. Sampson AP, Siddiqui S, Buchanan D, Howarth PH, Holgate ST, Holloway JW, et al. Variant $\mathrm{LTC}_{4}$ synthase allele modifies cysteinyl leukotriene synthesis in eosinophils and predicts clinical response to zafirlukast. Thorax 2000;55:528-31.

41. Asano K, Shiomi T, Hasegawa N, Nakamura H, Kudo H, Matsuzaki T, et al. Leukotriene $\mathrm{C} 4$ synthase gene $\mathrm{A}(-444) \mathrm{C}$ polymorphism and clinical response to a CYS-LT(1) antagonist, pranlukast, in Japanese patients with moderate asthma. Pharmacogenetics 2002;12:565-70.

42. Pavord ID, Tattersfield AE. Bronchoprotective role for endogenous prostaglandin $\mathrm{E}_{2}$. Lancet 1995;345:436-8.

43. Szczeklik A. Prostaglandin $E_{2}$ and aspirin-induced asthma. Lancet 1995; 345:1056. 